Fundamental movement skills testing in children with cerebral palsy

Catherine M. Capio

Cindy H.P. Sit

Bruce Abernethy

Institute of Human Performance

The University of Hong Kong 
FMS testing in children with cerebral palsy

\title{
Fundamental movement skills testing in children with cerebral palsy
}

\begin{abstract}
Purpose. To examine the inter-rater reliability and comparative validity of product-oriented and process-oriented measures of fundamental movement skills (FMS) among children with cerebral palsy $(\mathrm{CP})$.

Method. Thirty children with CP aged 6 to 14 years (Mean=9.83 SD 2.5), and classified in Gross Motor Function Classification System (GMFCS) levels I-III performed tasks of catching, throwing, kicking, horizontal jumping, and running. Process-oriented assessment was undertaken using a number of components of the Test of Gross Motor Development (TGMD-2), while product-oriented assessment included measures of time taken, distance covered and number of successful task completions. Cohen's Kappa, Spearman's rank correlation coefficient, and tests to compare correlated correlation coefficients were performed.

Results. Very good inter-rater reliability was found. Process-oriented measures for running and jumping had significant associations with GMFCS, as did seven product-oriented measures for catching, throwing, kicking, running, and jumping. Product-oriented measures of catching, kicking, and running had stronger associations with GMFCS than the corresponding process-oriented measures.
\end{abstract}

Conclusion. Findings support the validity of process-oriented measures for running and jumping, and of product-oriented measures of catching, throwing, kicking, running, and jumping. However, product-oriented measures for catching, kicking, and running appear to have stronger associations with functional abilities of children with $\mathrm{CP}$, and are thus recommended for use in rehabilitation processes.

Keywords: Fundamental movement skills, ICF-CY, GMFCS, Cerebral palsy, Children 
FMS testing in children with cerebral palsy

\section{INTRODUCTION}

Fundamental movement skills (FMS) are considered the essential basis for the development of more advanced and sport-specific motor skills [1]. FMS consist of two subgroups of skills that are performed in an upright or bipedal position: locomotor skills, and object control skills. Locomotor skills require overall movement of the body such as running and jumping [2,3]. In contrast object control skills, such as kicking, catching, and throwing, involve less whole-body translation and involve applying force to, or receiving force from, objects [1,4]. FMS are learned and acquired by children during the pre-pubertal years [5], and provide the essential foundation for the more complex actions [6] that underpin lifetime physical activity (PA) patterns [7]. High levels of FMS competence are considered to be prerequisite to the successful participation in sports and other types of regular PA [4,5], and past research has illustrated the positive association between FMS and PA levels in youngsters $[2,8,9]$. Since the ability to perform FMS has been identified as a potential factor that influences children's PA, it is important that this be measured using valid and reliable instruments [8] both for typically developing children and for children with disabilities.

One of the standardized measures of FMS for children is the Test of Gross Motor Development (TGMD). The TGMD identifies gross motor skills delay, assesses individual progress, aids in the development and evaluation of instructional programs, and functions as a measurement tool for research [3]. This instrument has demonstrated high internal consistency $(\alpha>0.80)$ and good content validity in that skills proficiency has been shown to increase in a linear manner with age $[3,10]$. It has also been used in studies involving children with different disabilities such as developmental coordination disorder (DCD) [11], intellectual disabilities [12], visual impairment [13], and autism spectrum disorders [14].

No studies, however, have been conducted to examine FMS in children with physical disabilities such as cerebral palsy (CP). FMS emerge within a dynamic system consisting of a specific task, a learner with specific characteristics, and a particular environment [15]. The biological factors associated with a physical disability result in a situation where the learner experiences motor constraints, which in effect, may retard the development of FMS in early childhood. Children with $\mathrm{CP}$, in particular, are affected by impairments that affect their ability to control movement and 
maintain stable positions [16]. While the hallmark of $\mathrm{CP}$ is a delay in the development of gross motor function [17], low levels of PA have also been observed [16,18] and related to motor functioning [19].

The nature and severity of the disturbance in motor function varies greatly in children with CP [20]. The Gross Motor Function Classification System (GMFCS) is the most widely-used classification system for the motor functioning of individuals with CP [21]. This standardized classification system emphasizes functions rather than limitations [22], has gained wide applicability, and has manifest consistency with the International Classification of Function, Health, and Disability (ICF) outlined by the World Health Organization [23]. GMFCS uses five levels that are based on differences in self-initiated movement, with emphasis on sitting and walking. It has also been validated against systematic and in-depth measures of gross motor abilities in children with CP [22], particularly measures of mobility skills and activities that require postural control [17,22].

FMS can be measured using product-oriented or process-oriented approaches [1]. Productoriented assessments are based on time, distance, or number of successful attempts resulting from the performance of a skill. Process-oriented assessments, conversely, are concerned with how the movement skills are performed and these assessments can be advantageous in accurately identifying impaired skill components [3]. The process-oriented approach evaluates movement skills based on expected patterns at each stage of development [1]. This approach, however, may not be adequate to assess the FMS of children with CP, as their performance of FMS (as a consequence of impairments associated with their condition) may not be carried out using typical movement patterns. In such a case, product-oriented measures are likely to be consistent with the philosophy underpinning the ICF model, which emphasizes the output of an individual rather than how the method of performance compares against a pre-determined "normal" standard [24]. The ICF model characterizes human functions into two categories: body functions and structures, and activities and participation [25]. Body structures are anatomical parts of the body, body functions refer to physiological functions of body systems, activities refer to execution of a task or action within a domain, and participation is an individual's performances in an actual life situation [26]. The components of human functions in this model have been made more specific for children through the ICF-CY (children and youth version) [27]. In the ICF-CY model, human function components account for developmental delay to serve as 
a basis for identifying children with increased risks of disabilities. The participation component, in particular, emphasizes social play and school context. Process-oriented approaches that evaluate movement patterns of FMS performance can contribute to identifying and quantifying developmental delay. On the other hand, product-oriented approaches to quantify the output of FMS performance may contribute to a more meaningful understanding of factors that relate to the participation component of the ICF-CY model.

An instrument that assesses the quantity of motor tasks that a child can complete rather than the quality of its pattern is the Gross Motor Function Measure (GMFM) [28]. It is a standardized instrument designed to measure motor function of children with $\mathrm{CP}$ in terms of five dimensions: lying/rolling, sitting, crawling/kneeling, standing, and walking/running/jumping. While GMFM is a quantitative measure of motor ability, the concept underlying it does not aim to test particular FMS such as throwing and catching [29].

Process-oriented FMS assessment, such as TGMD-2, can contribute to treatment planning as it identifies impairments [3]. Nevertheless, a product-oriented FMS testing strategy that can measure the output of a child with $\mathrm{CP}$, rather than the manner of performance, appears to be desirable. While GMFM measures the extent of abilities instead of the pattern of movement performance, its dimensions do not go beyond the locomotor skills of walking, running, and jumping. Valid productoriented measures may be crucial to examining the FMS proficiency of children with $\mathrm{CP}$ and how this proficiency changes in response to different interventions. It has been suggested that promotion of FMS may be a promising intervention towards facilitating adequate PA levels among children [30]. As we target FMS training among children with $\mathrm{CP}$, skill-specific testing procedures will be highly useful if they can provide proficiency measures that directly relate to expected task performances when children participate in sports and recreation. Previous studies have shown that childhood abilities in kicking, catching, and overhand throwing are significant predictors of children's PA [8] and physical fitness [31], and that jumping and running are the most commonly used locomotion skills in structured and unstructured play [32].

The purpose of the present study was to determine the inter-rater reliability and comparative validity of process-oriented and product-oriented FMS measurement procedures among children with 
CP. We used tests of associations to determine the cross-sectional convergent construct validity of product-oriented and process-oriented measures using GMFCS as a comparison measure. In the absence of a gold standard for measuring FMS proficiency in children with CP, GMFCS was selected as the comparison measure because it is the principal classification system of functional ability in this population. While GMFCS scores are ordinal in nature, it nevertheless provides a valid functional ability classification that reflects mobility skills and skills requiring postural control [17]. In this present study, we measured locomotor skills that result in overall movement of the body in space, and object control skills that require postural control in standing while applying or receiving forces from objects [1]. GMFCS has also been used as the criterion reference for testing the validity of other measurement scales used among children with CP [33]. Measurement scales for spasticity [34], manual dexterity [35], and motor ability [22] have all been developed and validated against GMFCS, but no scale has been found to focus on the evaluation of FMS. A valid approach at measuring FMS may contribute to understanding the domains of body structure and functions, and activities and participation in children with CP. As GMFCS provides a functional level classification system that is consistent with the ICF model, we hypothesized that product-oriented FMS measures would have significant associations with GMFCS functional levels amongst children with CP. We further hypothesized that the association of product-oriented measures with GMFCS would be significantly stronger than that of process-oriented measures, with the product-oriented measures predicted to be able to account for a greater amount of variance in the functional ability of children with CP than process-oriented measures.

\section{METHODS}

\section{Study participants}

Participants were a convenience sample of 30 children with CP (17 female, 13 male) aged between 6 to 14 years $(M=9.83$ years, $S D=2.5$ years $)$. Inclusion criteria were the ability to walk with or without walking aids and to follow 2-step commands. Exclusion criteria included neurologic disease and any other medical conditions that limited participation in physical activities. The participant sample consisted of children classified in GMFCS levels I ( $n=13)$, II, $(n=10)$, and III $(n=7)$. Parents 
provided written consent, and children gave verbal assent prior to study involvement. Ethical approval was granted by the Institutional Review Board (IRB) of the university.

\section{FMS Assessment}

\section{Process-oriented scores}

The components of TGMD-2 that evaluate the five FMS were used for process-oriented measurement. Each skill was evaluated in two trials, and skill performance was rated based on 3 to 4 qualitative criteria, depending on the specific skill. The presence or absence of a criterion was scored 1 or 0 , yielding a maximum score of 3-4 per trial. The details are presented in table 1.

\section{Product-oriented scores}

Performances of the two locomotor skills and the three object control skills were measured using product outputs based on duration, distance, and number of successful attempts [1]. For catching and throwing, product-oriented scores were measured based on the number of successful performances of the task ( $\mathrm{n} / 5$ trials), while the duration of task performance was measured for running (average of 3 trials in seconds). While the duration of task performance clearly measures skills that cover a pre-determined distance (e.g., running), it has been suggested that impairments in tone limit a person's ability to move quickly in complex tasks [36]. On account of this, duration of task performance was considered to be a potential product-oriented measure for kicking and jumping since the ability to move quickly may be relevant in the context of physical activity participation. As a result, three different product-oriented measures were taken for kicking: successful foot contact with the ball (n/5 trials), successful kick where the ball traveled at least 15 feet (n/5 trials), and duration of task performance (average of best 2 trials in seconds). On the other hand, two measures were taken for jumping: distance covered (average of best 2 trials in centimeters), and duration of task performance (average of best 2 trials in seconds). The detailed testing protocol and measures are also summarized in Table 1. 
Table 1 Testing protocol, product-oriented measures, and process-oriented criteria for the FMS tested.

\begin{tabular}{|c|c|c|c|c|}
\hline FMS & Materials $^{\mathrm{a}}$ & Directions & TGMD-2 Process-oriented Criteria ${ }^{\mathrm{b}}$ & Product-oriented Measures $^{\mathrm{c}}$ \\
\hline Catch & $\begin{array}{l}10 \text {-inch plastic ball } \\
15 \text { feet clear space }\end{array}$ & $\begin{array}{l}\text { The child and the test administrator stand } 15 \\
\text { feet apart. The ball is tossed in an underhand } \\
\text { manner directly to the child with a slight arc } \\
\text { aiming for his/her chest. The child is instructed } \\
\text { to catch the ball with both hands. }\end{array}$ & $\begin{array}{l}\text { 1. Preparation phase where hands are in front of the } \\
\text { body and elbows are flexed. } \\
\text { 2. Arms extend while reaching for the ball as it arrives. } \\
\text { 3. Ball is caught by hands only. }\end{array}$ & Number of successful catches ( $\mathrm{n} / 5$ trials) \\
\hline $\begin{array}{l}\text { Overhand } \\
\text { throw }\end{array}$ & $\begin{array}{l}\text { Tennis ball } \\
15 \text { feet clear space }\end{array}$ & $\begin{array}{l}\text { The child stands } 15 \text { feet away from a wall, and } \\
\text { is instructed to throw the ball hard towards the } \\
\text { wall. }\end{array}$ & $\begin{array}{l}\text { 1. Windup is initiated with downward movement of } \\
\text { hand/arm. } \\
\text { 2. Rotates hip and shoulders to a point where the non- } \\
\text { throwing side faces the wall. } \\
\text { 3. Weight is transferred by stepping with the foot } \\
\text { opposite the throwing hand. } \\
\text { 4. Follow through beyond ball release diagonally } \\
\text { across the body toward the non-preferred side. }\end{array}$ & $\begin{array}{l}\text { Number of successful throws where the ball } \\
\text { reached the wall ( } \mathrm{n} / 5 \text { trials) }\end{array}$ \\
\hline Run & $\begin{array}{l}\text { Two cones } \\
35 \text { feet clear space }\end{array}$ & $\begin{array}{l}\text { The cones are positioned } 15 \text { feet apart, with } 10 \\
\text { feet clear space before and after the cones. The } \\
\text { child stands } 10 \text { feet away from the first cone. } \\
\text { The child is instructed to run past the second } \\
\text { cone, as fast as he/she can when the tester says } \\
\text { "GO". }\end{array}$ & $\begin{array}{l}\text { 1. Arms move in opposition to legs, elbows bent. } \\
\text { 2. Brief period where both feet are off the ground. } \\
\text { 3. Narrow foot placement landing on heel or toe (not } \\
\text { flat footed). } \\
\text { 4. Nonsupport leg bent approximately } 90 \text { degrees } \\
\text { (close to buttocks). }\end{array}$ & $\begin{array}{l}\text { Mean duration of run between two cones out of } \\
3 \text { trials (in seconds) }\end{array}$ \\
\hline Kick & $\begin{array}{l}12 \text {-inch rubber ball } \\
20 \text { feet clear space }\end{array}$ & $\begin{array}{l}\text { The child stands } 20 \text { feet away from a wall. The } \\
\text { ball is placed between the wall and the child at } \\
\text { a distance of } 5 \text { feet. The child is instructed to } \\
\text { run/walk up and kick the ball hard towards the } \\
\text { wall. }\end{array}$ & $\begin{array}{l}\text { 1. Rapid continuous approach to the ball. } \\
\text { 2. An elongated stride or leap immediately prior to ball } \\
\text { contact. } \\
\text { 3. Non-kicking foot placed even with or slightly back } \\
\text { of the ball. }\end{array}$ & $\begin{array}{l}\text { Number of successful kicks where the child hit } \\
\text { the ball with his/her dominant foot ( } \mathrm{n} / 5 \text { trials) } \\
\text { Number of successful kicks where the ball } \\
\text { reached the wall ( } \mathrm{n} / 5 \text { trials) } \\
\text { Mean duration from start of run-up to contact of } \\
\text { child's foot and ball out of the best } 2 \text { trials (in } \\
\text { seconds) }\end{array}$ \\
\hline $\begin{array}{l}\text { Horizontal } \\
\text { jump }\end{array}$ & 10 feet clear space & $\begin{array}{l}\text { The child stands just behind the starting mark } \\
\text { of the } 10 \text { feet clear space. The child is } \\
\text { instructed to jump forward as far as he/she can. }\end{array}$ & $\begin{array}{l}\text { 1. Preparation phase where both knees are flexed, with } \\
\text { arms extended behind the body. } \\
\text { 2. Arms extend forcefully forward and upward } \\
\text { reaching full extension above the head. } \\
\text { 3. Take off and land on both feet simultaneously. } \\
\text { 4. Arms are thrust downward during landing. }\end{array}$ & $\begin{array}{l}\text { Mean distance of space cleared by the jump } \\
\text { from starting point to landing point out of the } \\
\text { best } 2 \text { trials (in centimeters) } \\
\text { Mean duration of time from preparation to } \\
\text { landing out of the best } 2 \text { trials (in seconds) }\end{array}$ \\
\hline
\end{tabular}

\footnotetext{
${ }^{\text {a }}$ Adapted with modifications from:Ulrich D. Test of Gross Motor Development. 2nd ed. Texas: Pro-Ed; 2000. The materials and directions are the same for both process-oriented and productoriented assessments.

oriented assessments.
${ }^{b}$ Each process-oriented criterion is scored 1 when present, and 0 when absent. Each FMS is performed for 2 trials, thus, maximum possible total scores range from 6 to 8.

${ }^{c}$ One product-oriented score each for catch, throw, and run; three parameters for kick scores; two parameters for jump scores.
} 
FMS testing in children with cerebral palsy

\section{Comparison measure}

Each participant was classified in the Gross Motor Function Classification System (GMFCS) as levels I to III, and this was used as the criterion measure. GMFCS, a classification system designed for children with CP, uses 5 levels based on abilities in self-initiated movement and locomotion [22]. Level I denoted the ability to walk without any restrictions, Level II referred to walking with limitations when outdoors in the community, Level III referred to walking with assistive mobility devices, and Levels IV and V described mobility patterns where the children are in supported sitting and powered assistive technology are used.

\section{Procedures}

Testing procedures for the FMS assessment were adapted and modified from the protocols of the second edition of TGMD (TGMD-2) [3]. To adjust to the facilities in the study site, the materials were modified in terms of size of balls and available clear space. This was considered acceptable since we did not intend to analyze TGMD-2 scores against established norms. Participants were asked to engage in individual testing sessions, which included the performance of catching, throwing, kicking, jumping for distance, and running. For throwing and kicking, participants were instructed to use whichever side (left or right) that they felt would result in the best possible performance. Participants confirmed post-hoc, that each one used his/her dominant side. For participants with spastic hemiplegia, their dominant side was also their unaffected side. In kicking, those with hemiplegia used their unaffected side as the weight-bearing leg and the affected leg for the kicking action.

All data were collected on normal school days at special schools during a 30-minute break period. Sessions were conducted outdoors, in the school's designated playground which had non-slip rubber mat surfaces to minimize injuries in case of falling or tripping. The playground was located in a square, at the center of the school buildings, which effectively blocked any significant wind movements that might have affected object control performance and also provided shade to the testing area. Testing days were conducted in the month of October, during which there was no rain and outdoor air temperature of $23-29{ }^{0} \mathrm{C}$ [37] fell within the comfortable range [38]. The designated testing section of the playground was enclosed by waist-level barriers, and only participants who were currently being tested were allowed in the area. 
All tests were administered by the first author who is a qualified and experienced physiotherapist. Verbal instructions were given using a maximum of two-step commands, followed by demonstrations. Five trials were done for catching, throwing, and kicking, while three trials were done for jumping and running. In each of the skills, the last two trials were rated using process-oriented measures. All five trials for catching, throwing, and kicking were counted in determining the measures of successful performance. For measures of duration and distance, the average of the best two trials was taken.

The physiotherapist-in-charge of each participant was present during the testing sessions and recorded the product-oriented scores immediately after each trial. Video recordings were taken, which were later analyzed by the first author using both product-oriented and process-oriented parameters. A second rater conducted process-oriented assessment of the participants' performances based on the video recordings. Both raters for process-oriented measures are physiotherapists with at least two years of clinical practice and are familiar with the use of TGMD-2 and GMFM. Calibration was established prior to analyzing the video recordings by having both raters review the criteria for overhand throwing in TGMD-2. Two children with CP who were not part of the study sample were subsequently evaluated by both raters, and results were found to be consistent.

Inter-rater reliability was examined using Cohen's Kappa coefficient, and agreement between raters based on Kappa values was interpreted as follows: $<0.20$ as poor, $0.21-0.40$ as fair, $0.41-0.60$ as moderate, $0.61-0.80$ as good, and $>0.80$ as very good [39]. Considering the relatively small sample size and that GMFCS scores are ordinal, Spearman's rank correlation coefficient was computed for each process- and product-oriented measure and GMFCS. Associations of GMFCS with productoriented and process-oriented measures for each tested FMS were compared using the statistical test to compare correlated correlation coefficients as suggested by Meng, Rosenthal, and Rubin [40]. Onetailed significance level was set at $p<0.05$.

\section{RESULTS}

The median GMFCS classification level of the participants was I, with the range being I to III. Descriptive summaries (mean, 95\% confidence interval, and standard deviation) of process-oriented scores are summarized in Table 2, while product-oriented scores are summarized in Table 3. 
Table 2 Mean, 95\% confidence interval (CI), and standard deviation (SD) of participants' process-oriented scores.

\begin{tabular}{lcc}
\hline \multicolumn{1}{c}{ FMS (maximum score) } & Mean $(95 \%$ CI) & $S D$ \\
\hline Catching (6) & $2.05(1.08-3.02)$ & 2.01 \\
Throwing (8) & $3.21(2.34-4.08)$ & 1.81 \\
Kicking (8) & $3.79(2.99-4.59)$ & 1.65 \\
Running (8) & $3.21(2.00-4.42)$ & 2.51 \\
Jumping (8) & $3.32(2.36-4.27)$ & 1.97 \\
\hline
\end{tabular}

Table 3 Mean, 95\% confidence interval (CI), and standard deviation (SD) of participants' product-oriented scores.

\begin{tabular}{lcc}
\hline \multicolumn{1}{c}{ FMS (criterion) } & Mean (95\% CI) & SD \\
\hline $\begin{array}{l}\text { Catching } \\
\text { (successful performances) }\end{array}$ & $2.37(1.50-3.24)$ & 1.80 \\
$\begin{array}{l}\text { Throwing } \\
\text { (successful performances) }\end{array}$ & $3.79(2.90-4.68)$ & 1.84 \\
$\begin{array}{l}\text { Kicking } \\
\text { (successful performances) }\end{array}$ & $4.84(4.67-5.00)$ & 0.37 \\
$\begin{array}{l}\text { Kicking where ball travelled } 15 \text { feet } \\
\text { (successful performances) }\end{array}$ & $4.26(3.90-4.62)$ & 0.73 \\
$\begin{array}{l}\text { Kicking } \\
\text { (duration in seconds) }\end{array}$ & $2.21(1.8-2.59)$ & 0.79 \\
$\begin{array}{l}\text { Running } \\
\text { (duration in seconds) }\end{array}$ & $4.37(3.58-5.16)$ & 1.64 \\
$\begin{array}{l}\text { Jumping } \\
\text { (distance in centimeters) }\end{array}$ & $71.89(47.37-96.42)$ & 50.89 \\
$\begin{array}{l}\text { Jumping } \\
\text { (duration in seconds) }\end{array}$ & $1.68(1.36-2.01)$ & .67 \\
\hline
\end{tabular}

\section{Reliability}

Inter-rater reliability for the five process-oriented measures was found to be very good (Cohen's Kappa: $0.875-0.907)$. Similarly, very good inter-rater reliability was found for the eight productoriented measures (Cohen's Kappa: $0.953-1.00)$.

\section{Validity}

Table 4 shows the correlation coefficients $(r)$ and the coefficients of determination $(R 2)$ between GMFCS levels and process-oriented measures and product-oriented measures. Significant negative associations were found between GMFCS levels and process-oriented scores for running and jumping 
(both $p=0.01$ ), explaining $24 \%$ and $26 \%$ of the variance in GMFCS levels respectively. For productoriented measures, GMFCS levels were positively associated with kicking duration, running, and jumping duration; and were negatively associated with successful performance of catching and throwing, kicking distance, and jumping distance. All product-oriented measures except number of successful kick (contact between foot and ball) were found to have significant associations with GMFCS levels (all $p<0.05)$.

Comparison of dependent correlation coefficients showed that GMFCS levels had stronger associations with product-oriented than process-oriented scores in catching $(p=.005)$, kicking duration $(p=.009)$, and running $(p=0.01)$. Correlation coefficients between GMFCS and productoriented and process-oriented scores in throwing, jumping, and two kicking parameters (contact and distance) did not show statistically significant differences. These are also shown in table 4.

Table 4 Correlation coefficients (r) and coefficients of determination (R2) between GMFCS levels and processoriented and product-oriented scores.

\begin{tabular}{|c|c|c|c|c|c|c|}
\hline \multirow[b]{2}{*}{ FMS } & \multicolumn{2}{|c|}{ Process-oriented } & \multicolumn{2}{|c|}{ Product-oriented } & \multicolumn{2}{|c|}{ Comparison } \\
\hline & $r\left(R^{2}\right)$ & $\begin{array}{c}p \\
\text { (one-tailed) }\end{array}$ & $r\left(R^{2}\right)$ & $\begin{array}{c}p \\
\text { (one-tailed) }\end{array}$ & $Z$ & $p$ \\
\hline \multicolumn{7}{|l|}{ Object Control Skills } \\
\hline Catching & $-.152(.02)$ & .212 & $-.579(.34)$ & $.000^{\mathrm{a}}$ & 2.57 & $.005^{\mathrm{a}}$ \\
\hline Throwing & $-.124(.02)$ & .257 & $-.33(.11)$ & $.038^{\mathrm{a}}$ & 1.28 & .10 \\
\hline Kicking & $-.194(.04)$ & .153 & & & & \\
\hline Kicking (contact) & & & $.273(.07)$ & .072 & 0.32 & 0.37 \\
\hline Kicking (distance) & & & $-.378(.14)$ & $.020^{\mathrm{a}}$ & 1.21 & 0.11 \\
\hline Kicking (duration) & & & $.632(.40)$ & $.000^{\mathrm{a}}$ & 2.37 & $.009^{\mathrm{a}}$ \\
\hline \multicolumn{7}{|l|}{ Locomotor Skills } \\
\hline Running & $-.488(.24)$ & $.003^{\mathrm{a}}$ & $.765(.59)$ & $.000^{\mathrm{a}}$ & 2.30 & $0.01^{\mathrm{a}}$ \\
\hline Jumping & $-.506(.26)$ & $.002^{\mathrm{a}}$ & & & & \\
\hline Jumping (distance) & & & $-.464(.28)$ & $.005^{\mathrm{a}}$ & -0.58 & 0.22 \\
\hline Jumping (duration) & & & $.516(.46)$ & $.012^{\mathrm{a}}$ & 0.10 & 0.46 \\
\hline
\end{tabular}

$\overline{\text { statistically significant }}$

\section{DISCUSSION}

Current rubrics for measurement of function and abilities in children with $\mathrm{CP}$ still appear to be inadequate [41]. In particular, this study focused on measuring FMS for purposes of evaluating a child's potential to participate in sports and recreation activities. Similar to validation studies of other measurement scales, we used GMFCS as the comparison measure to examine the validity of processoriented and product-oriented measures for catching, throwing, kicking, jumping, and running skills. 
Our results showed significant associations between GMFCS and process-oriented measures of running and jumping, and significant associations between GMFCS and product-oriented measures for all five skills. Furthermore, product-oriented measures for catching, kicking, running, and jumping were found to predict substantial (> 20\%) variance in GMFCS levels, offering evidence of the validity of these measures for use among children with CP. GMFCS has been known to be consistent with the ICF model of classification [24], and comparisons of the measures for the tested FMS skills indicated that a product-oriented measurement approach may potentially have greater compatibility with the ICF model.

\section{Object control skills}

Catching may be described as a multi-segmental action of reaching and grasping [42], requiring coordination along with timing at the precise moment that the oncoming ball reaches the person [43]. Task success may be achieved in different ways. Individuals who catch a ball may do so using different movement patterns yet ultimately still receive the object using one or two hands. Thus, successful task performance (product-oriented) may occur even with developmentally delayed movement patterns (process-oriented). The findings of this study confirmed that product-oriented measures were reflective of functional level in children with CP.

The improvement of kicking skills among children has been documented to show decreased duration of the run-up phase [44]. Consistent with this, we found that children with higher levels of functional ability were able to perform kicking within a shorter duration. The faulty control of movement among children with more severe levels of CP impairment [16] may result in a longer duration of time required to perform complex tasks. As such, the measure of duration of task performance in kicking was also found to be more reflective of the functional level of children with $\mathrm{CP}$, relative to a measure of kicking movement pattern. While we found that the ability to kick over a specified distance also had a positive association with the functional level of the participants, this product-oriented measure was not found to be significantly better than a process-oriented measure. The number of successful contact between the ball and the foot did not have a significant association with functional levels, possibly due to the narrow distribution of participants' scores in this parameter. 
This suggests that mere contact between a child's foot and the ball while attempting to kick, does not reflect their functional abilities.

Successful task performance of overhand throwing was found to be associated with functional abilities, but to a weak extent such that this measure predicted only $11 \%$ of the variance in GMFCS levels. Overhand throwing is a complex task of energy generation and transfer from proximal body parts to distal part of the upper extremities [45], and this might well be affected by the impaired movement control of children with CP. It seemed that besides the actual throwing movement, other measures of performance (e.g., distance covered by the object that was thrown, accuracy of hitting a throwing target) might account for more variance of the functional levels of children with CP. This suggests that other product-oriented measures might be necessary to assess throwing. Alternatively, the relatively weaker association between throwing and GMFCS might also be explained by the fact that the classification of GMFCS levels is primarily related to self-initiated mobility [22]. While the optimum movement pattern of overhand throwing requires trunk rotation and leg movements, the main action involves arm and hand functions [3]. Consequently, successful performance of overhand throwing may have limited association with functional level.

\section{Locomotor skills}

Jumping has been known to be a required skill in a number of athletic pursuits, and the horizontal jump has been measured based on the distance covered from a starting line to the heel of the nearer landing foot [46]. While we found this measure to reflect the functional abilities of our sample, the duration of task performance appeared to be an equally valid measure of jumping. Similarly, running speed (duration of task performance) was found to be associated with functional level, with those with more severe CP impairments taking longer to complete the task. Greater levels of impairment, associated with the disordered control of movement among individuals with CP [20], may result in slower execution of locomotor skills, thus affecting the outcome in terms of duration.

Considering that the main impairment associated with $\mathrm{CP}$ relates to motor functioning and organization [20], it was expected that the movement patterns of the children with $\mathrm{CP}$ while performing FMS may not be developmentally mature and would result in poor FMS performance. Using the ICF model as a framework, we hypothesized that measures of FMS output (product- 
oriented) may be more representative of the functional abilities of these children. We confirmed this hypothesis in three FMS using the number (catching) and duration (kicking, running) of successful task performance. While mature movement patterns are indicators of proficient FMS that may translate to successful participation in sports and physical activities [5], this does not necessarily mean that developmentally delayed movement patterns will prevent children's engagement in games and sports.

\section{Limitations}

The FMS measures employed in this study were focused selectively on a sample of skills that have been found to be relevant in common sports. As such, the measures do not provide an overall evaluation of a child's FMS proficiency. Furthermore, our inclusion criterion that the participants should be able to walk independently limited our sample to children who were within GMFCS levels I to III. While this was important in testing locomotor skills, we acknowledge that children in GMFCS level IV may actually participate in some object control skills while seated on a wheelchair. Further validation of FMS measures for wheelchair-bound participants may be of interest in relation to adapted sports in which children with CP may be engaged.

\section{CONCLUSION}

In applying the ICF model to children with $\mathrm{CP}$, it has been argued that what an individual is able to do is more important than how the task is performed [24]. Consistent with this philosophy we used product-oriented measures that evaluated the task performance with observable data, and were not based on a pre-conception of what the most appropriate movement pattern would look like. Our findings demonstrated that product-oriented measures for catching, throwing, kicking, jumping, and running were valid in children with $\mathrm{CP}$. We suggest that catching and throwing could be measured by the number of successful performances, while kicking by the duration of task performance. We also suggest that jumping could be assessed by the distance covered and the duration of task performance, and running by the duration of task performance over a set distance. These measures may be applicable even to typically developing children without concern for effects of bias related to preconceptions of what constitutes the ideal movement pattern. 
Overall, we conclude that product-oriented measures appear to be more appropriate than process-oriented measures in testing catching, kicking, and running for children with CP. Productoriented and process-oriented measures for jumping were found to be equally valid for the same population. While product-oriented measures for throwing were found to have significant associations with functional ability, these were not found to be significantly better than process-oriented measures, and thus require further examination. In the context of research, the use of tests is highly dependent on the purpose of a study [47]. The FMS measures that were validated in this study are geared for further research that would examine associations between FMS and PA levels. As such, we examined skills that children will use in sport and recreation activities.

The ICF-CY model has been found to be useful in guiding assessment, goal setting, treatment planning and monitoring, and outcome measurement in children [48]. Consistent with the ICF model of human functions, process-oriented FMS measures may contribute to the design of techniques and strategies that address developmental delay and impact body structures and functions, and activities. On the other hand, product-oriented FMS assessment evaluates outputs that may be relevant in facilitating heightened participation in social play and school-based games. Dynamic interaction exists between ICF domains of function such that participation restrictions may be inferred from impairments in body structures [23]. However, it has been emphasized that data on these constructs need to be collected independently in order to describe the full health experience [27]. It is thus suggested that product-oriented FMS measures such as those validated in this study contribute assessment data that are relevant in designing, implementing, and monitoring rehabilitation procedures. Moreover, combination of both process- and product-oriented approaches in FMS testing stands to generate a comprehensive understanding of FMS-related functional domains of a child with CP.

\section{ACKNOWLEDGEMENTS}

The authors would like to thank Tina Chan, PT and Kathlynne Eguia, PT for facilitating the data collection. Special thanks go to the participating children with $\mathrm{CP}$, to their parents, and to their physiotherapists. 


\section{DECLARATION OF INTEREST}

The authors report no declarations of interest.

\section{REFERENCES}

1. Burton A, Miller D. Movement skill assessment. . Champaigne, IL: Human Kinetics; 1998.

2. Okely AD, Booth ML, Patterson JW. Relationship of physical activity to fundamental movement skills among adolescents. Medicine and Science in Sports and Exercise 2001;33(11):1899-1904.

3. Ulrich D. Test of Gross Motor Development. . Texas: Pro-Ed; 2000.

4. Jaakkola T, Kalaja S, Liukkonen J, Jutila A, Virtanen P, Watt A. Relations among physical activity patterns, lifestyle activities, and fundamental movement skills for Finnish students in grade 7. Percept Mot Skills 2009;108(1):97-111.

5. Gallahue D, Ozmun J. Understanding motor development Infants, children, adolescents, adults. Massachusetts: McGraw-Hill; 1998.

6. Getchell N. Age and task-related differences in timing stability, consistency, and natural frequency of children's rhythmic, motor coordination. Dev Psychobiol 2006;48(8):675-85.

7. Haywood K, Getchell N. Life Span Motor Development. Champaigne, IL: Human Kinetics; 2005.

8. Barnett LM, van Beurden E, Morgan PJ, Brooks LO, Beard JR. Childhood motor skill proficiency as a predictor of adolescent physical activity. J Adolesc Health 2009;44(3):252-9.

9. Wrotniak BH, Epstein LH, Dorn JM, Jones KE, Kondilis VA. The relationship between motor proficiency and physical activity in children. Pediatrics 2006;118(6):e1758-65.

10. Aponte R, French R, Sherrill C. Motor Development of Puerto-Rican Children Cross-Cultural Perspectives. Perceptual and Motor Skills 1990;71(3):1200-1202.

11. Niemeijer AS, Smits-Engelsman BCM, Schoemaker MM. Neuromotor task training for children with developmental coordination disorder: a controlled trial.

Developmental Medicine and Child Neurology 2007;49(6):406-411.

12. Simons J, Daly D, Theodorou F, Caron C, Andoniadou E. Validity and reliability of the TGMD-2 in 7-10-year-old Flemish children with intellectual disability. Adapt Phys Activ Q 2008;25(1):71-82.

13. Houwen S, Visscher C, Hartman E, Lemmink KAPM. Gross motor skills and sports participation of children with visual impairments. Research Quarterly for Exercise and Sport 2007;78(2):16-23.

14. Staples KL, Reid G. Fundamental movement skills and autism spectrum disorders. J Autism Dev Disord 2010;40(2):209-17.

15. Goodway JD, Branta CF. Influence of a motor skill intervention on fundamental motor skill development of disadvantaged preschool children. Research Quarterly for Exercise and Sport 2003;74(1):36-46.

16. Bjornson KF, Belza B, Kartin D, Logsdon R, McLaughlin J, Thompson EA. The relationship of physical activity to health status and quality of life in cerebral palsy. Pediatr Phys Ther 2008;20(3):247-53. 
17. Rosenbaum P, Walter SD, Hanna SE, Palisano RJ, Russell DJ, Raina P, Wood E, Bartlett DJ, Galuppi BE. Prognosis for gross motor function in cerebral palsy: creation of motor development curves. JAMA 2002;288(11):1357-63.

18. Engel-Yeger B, Jarus T, Anaby D, Law M. Differences in Patterns of Participation Between Youths With Cerebral Palsy and Typically Developing Peers. American Journal of Occupational Therapy 2009;63(1):96-104.

19. Palisano RJ, Copeland WP, Galuppi BE. Performance of physical activities by adolescents with cerebral palsy. Physical Therapy 2007;87(1):77-87.

20. Rosenbaum P, Paneth N, Leviton A, Goldstein M, Bax M, Damiano D, Dan B, Jacobsson B. A report: the definition and classification of cerebral palsy. Dev Med Child Neurol Suppl 2007;109:8-14.

21. Palisano RJ, Rosenbaum P, Walter S, Russell D, Wood E, Galuppi B. Development and reliability of a system to classify gross motor function in children with cerebral palsy. Dev Med Child Neurol 1997;39(4):214-23.

22. Palisano RJ, Hanna SE, Rosenbaum PL, Russell DJ, Walter SD, Wood EP, Raina PS, Galuppi BE. Validation of a model of gross motor function for children with cerebral palsy. Phys Ther 2000;80(10):974-85.

23. WHO. International classification of functioning, disability, and health: ICF. Geneva: World Health Organization; 2001.

24. Rosenbaum P, Stewart D. The World Health Organization International Classification of Functioning, Disability, and Health: a model to guide clinical thinking, practice and research in the field of cerebral palsy. Semin Pediatr Neurol 2004;11(1):5-10.

25. Grill E, Stucki G. Scales could be developed based on simple clinical ratings of International Classification of Functioning, Disability and Health Core Set categories. J Clin Epidemiol 2009;62(9):891-8.

26. Ustun TB, Chatterji S, Bickenbach J, Kostanjsek N, Schneider M. The International Classification of Functioning, Disability and Health: a new tool for understanding disability and health. Disabil Rehabil 2003;25(11-12):565-71.

27. WHO. International classification of functioning, disability, and health: children and youth version: ICF-CY. Geneva: World Healthh Organization; 2007.

28. Russell DJ, Rosenbaum P, Avery L, Lane M. Gross motor function measure (GMFM 66 \& GMFM 88): User's manual. London: McKeith Press; 2002.

29. Russell DJ, Avery LM, Rosenbaum P, Raina PS, Walter SD, Palisano RJ. Improved scaling of the gross motor function measure for children with cerebral palsy: evidence of reliability and validity. Phys Ther 2000;80(9):873-85.

30. Salmon J, Ball K, Hume C, Booth M, Crawford D. Outcomes of a group-randomized trial to prevent excess weight gain, reduce screen behaviours and promote physical activity in 10-year-old children: switch-play. Int J Obes (Lond) 2008;32(4):601-12.

31. Barnett LM, Van Beurden E, Morgan PJ, Brooks LO, Beard JR. Does Childhood Motor Skill Proficiency Predict Adolescent Fitness? Medicine and Science in Sports and Exercise 2008;40(12):2137-2144.

32. McKenzie TL, Sallis JF, Broyles SL, Zive MM, Nader PR, Berry CC, Brennan JJ. Childhood movement skills: Predictors of physical activity in Anglo American and Mexican American adolescents? Research Quarterly for Exercise and Sport 2002;73(3):238-244.

33. Morris C, Bartlett D. Gross motor function classification system: impact and utility. Developmental Medicine and Child Neurology 2004;46(1):60-65.

34. Nordmark E, Andersson G. Wartenberg pendulum test: objective quantification of muscle tone in children with spastic diplegia undergoing selective dorsal rhizotomy. Developmental Medicine and Child Neurology 2002;44(1):26-33. 
35. Beckung E, Hagberg G. Neuroimpairments, activity limitations, and participation restrictions in children with cerebral palsy. Developmental Medicine and Child Neurology 2002;44(5):309-316.

36. Shumway-Cook A, Woollacott MH. Motor Control: Theory and Practical Applications. Maryland: Lippincott Williams \& Wilkins; 2001.

37. HKO. 17 March. Climatologic information enquiry. Hong Kong Observatory $<$ http://www.hko.gov.hk/cis/enquiry_e.htm>. Accessed 201117 March.

38. ASHRAE. Thermal environmental conditions for human occupancy. 2008.

39. Altman DG. Practical statistics for medical research. London: Chapman and Hall; 1991.

40. Meng XL, Rosenthal R, Rubin DB. Comparing Correlated Correlation-Coefficients. Psychological Bulletin 1992;111(1):172-175.

41. Adams JV. Understanding function and other outcomes in cerebral palsy. Physical Medicine and Rehabilitation Clinics of North America 2009;20:567-575.

42. Jobling A, Mon-Williams M. Motor development in Down Syndrome: A longitudinal perspective. In: Elliot D, Weeks D, Chua R, editors. Perceptual-Motor Behavior in Down Syndrome. London: Human Kinetics; 2000.

43. Capio CM, Rotor ER. Fundamental movement skills among Filipino children with Down Syndrome. Journal of Exercise Science and Fitness 2010;8(1):17-24.

44. van Eck M, Dallmeijer AJ, Beckerman H, van den Hoven PAM, Voorman JM, Becher JG. Physical activity level and related factors in adolescents with cerebral palsy. Pediatric Exercise Science 2008;20(1):95-106.

45. Fleisig GS, Barrentine SW, Escamilla RF, Andrews JR. Biomechanics of overhand throwing with implications for injuries. Sports Med 1996;21(6):421-37.

46. Wang WY, Ju YH. Promoting balance and jumping skills in children with down syndrome. Perceptual and Motor Skills 2002;94(2):443-448.

47. Cools W, De Martelaer K, Samaey C, Andries C. Movement skill assessment of typically developing preschool children: A review of seven movement skill assessment tools. Journal of Sports Science and Medicine 2009;8(2):154-168.

48. Bjorck-Akesson E, Wilder J, Granlund M, Pless M, Simeonsson R, Adolfsson M, Almqvist L, Augustine L, Klang N, Lillvist A. The International Classification of Functioning, Disability and Health and the version for children and youth as a tool in child habilitation/early childhood intervention--feasibility and usefulness as a common language and frame of reference for practice. Disabil Rehabil 2010;32 Suppl $1:$ S125-38. 